Theories \& Applications, the International Edition

Printed Version: (ISSN 2090-5262)

Online Version: (ISSN 2090-5270)

July 2013, Volume 3, No. 2 Pages (203 - 210)

\title{
Obstacles Facing Tennis Players in the Arab Republic of Egypt
}

\author{
Labib Abdel Aziz Labib*
}

\begin{abstract}
The research aims to identify the obstacles facing the tennis players in the Arab Republic of Egypt to be able to create the appropriate atmosphere that will allow these players to achieve their highest levels by determining these obstacles and try to find solutions through administrative, financial, organizational, coaching, and officiating domains. The researcher used the descriptive method because it is suitable to the nature of the research. The research was carried out on a deliberated classified sample of tennis players under 18 years old. The sample size was (116) players of the total (208) players registered in the ranking lists and with the percentage of (56\%) of the total sample. The female players sample was 87 of the total (121) female players registered in the ranking lists with a percentage of $(72 \%)$ of the total volume. Dates of tennis championships are not convenient to most of the tennis players. There is no encouragement from school to the tennis players. Practicing tennis has negatively affected the academic achievement of the tennis players.
\end{abstract}

\section{Introduction}

$\mathrm{T}$ ennis is one of the fast-spreading activities in many countries of the world as it has witnessed a continuous growth in the number of participants due to its nature and what it represents of fun for players and spectators. Tennis has special ethics and traditions which contribute to the upgrading of the behavior of all tennis players, as well as it is like any other competitive sport which has physical, skill and tactic requirements, in addition, it requires hard work and highly administrative abilities as well as continuous regular training for long periods in order to achieve the highest levels in this activity (11).

B. Berracci (1982) believes that it is high time for the use of advanced methods that enables coaches to reach with their players to their highest levels so that it benefit them in good leading of their players in competitions and championships in which they participated in, however, those methods should be easily followed (14).

Tennis has first appeared as we known it

* Assistant Professor, Department of Fundamentals of Physical Education and Recreation, Faculty of Physical Education, Menoufia University, Egypt. nowadays in France, where the French people were known as kings of this game, later on, it spread to the rest of Europe and the whole world (10). Tennis has entered Egypt by the British people as it was practiced by the aristocratic people, where Gezira Sporting Club was the most important club that sponsor tennis as they organized the Egypt International Championship in 1907 before the establishment of the Egyptian Tennis Federation in 1920 (2).

At present, the spread of tennis in Egypt increased and it was accompanied by a significant increase in the numbers of players. Tennis players has several commitments that they must abide by until reaching a high level of performance, winning the championships and attain victories, for doing so, they should be serious, trained hard and taking part in competitions, which in turn requires time, effort and endurance because training requires greater time, effort and expenses which may not be available for all social classes as well as competitions and its requirement of legal obligations and regulations established by the International Tennis Federation (15), beside all other aspects that would help the player to reach top performance. In order for tennis player to achieve these, all means that helps him should 
be studied as well as identifying the obstacles he faces.

The researcher, through his work in the field of tennis for 25 years, noted that there are some obstacles that impede the progress of tennis players. Despite the large number of players on the national level, still there are several obstacles exist, including administrative, financial, organizational, coaching and officiating obstacles. By trying to recognize these obstacles and overcome them, this may have a significant influence on the technical upgrading of the game and the players as well as achieving a better level on this sport.

Hence, the importance of this research is significant because it identifies the obstacles facing tennis players in the Arab Republic of Egypt and tries to find solutions to them in order to realize a real progress in the field of tennis.

\section{Objective of the Research}

The research aims to identify the obstacles facing the tennis players in the Arab Republic of Egypt to be able to create the appropriate atmosphere that will allow these players to achieve their highest levels by determining these obstacles and try to find solutions through the following domains:

1. Administrative domain

2. Financial domain

3. Organizational domain

4. Coaching domain

5. Officiating domain

\section{Search Proceedings}

\section{Research Methodology}

The researcher used the descriptive method because it is suitable to the nature of the research.

\section{The Research Sample}

The research was carried out on a deliberated classified sample of tennis players under 18 years old. The sample size was (116) players of the total (208) players registered in the ranking lists and with the percentage of $(56 \%)$ of the total sample. The female players sample was 87 of the total (121) female players registered in the ranking lists with a percentage of $(72 \%)$ of the total volume.

\section{Data Collection Tools}

Questionnaire on the obstacles facing tennis players in the Arab Republic of Egypt

\section{The Preparation of the Questionnaire}

The researcher prepared the Questionnaire Form by asking tennis players, administrative personnel, officials and parents about the obstacles and problems they face in tennis, as well as briefing them with the scientific references and studies related. The researcher reviewed also the reports of the officials of the championship to identify the notes and obstacles they faced in tennis competitions to determine the initial form of the questionnaire and its domains as well as phrases of each domain and how much these phrases are appropriate to each domains as well as the objectives of the research. All these items had been introduced in its initial form to the officials who have experience in the field of tennis.

\section{Reliability of the Questionnaire}

\section{Honesty of the Officials}

The researcher presented the questionnaire in its initial form to (5) of the officials and specialists in the field of tennis (Attachment no.1) so as to express their opinion about the domains of the questionnaire.

The officials agreed that the questionnaire is valid for application in its final form, and it includes 5 domains, with 58 phrases -after the deletion of the phrases in which the agreement ratio of the officials was less than $80 \%$ - as well as modifying certain phrases based on the opinions of the officials.

It was also agreed to use triple scale to estimate the response of responders.

\section{The Stability of the Questionnaire}

The researcher calculates the coefficient reliability of the questionnaire on obstacles facing tennis players in the Arab Republic of Egypt on a sample size of (34) male and female classified in the Egyptian Tennis Federation from outside the research sample.

By calculating the reliability coefficient by using retail midterm, alpha coefficient, for the 
first half of the questionnaire, was 0.75 while the second half of the phrases was 0.518 . These two values are significant at the level of 0.01 .

\section{Application of the Questionnaire}

After making sure of the scientific coefficient of the questionnaire and preparing its final form, Presenting and Discussing Results the researcher apply the questionnaire during the Republic Tennis Championships held at Tawfikia Tennis Club - Surf Tennis Academy Stars Academy during the period from 6-21 October 2012.

Table (5)

Statistical characterization, frequencies and percentages of research sample responses on the administrative domain $N=203$

\begin{tabular}{|c|c|c|c|c|c|c|c|c|c|c|}
\hline \multicolumn{2}{|c|}{ Officiating } & \multicolumn{2}{|c|}{ Coaching } & \multicolumn{2}{|c|}{ Organization } & \multicolumn{2}{|c|}{ financial } & \multicolumn{2}{|c|}{ Administrative } & \multirow{2}{*}{ sentences } \\
\hline $\begin{array}{c}\text { Relative } \\
\text { importa } \\
\text { nce }\end{array}$ & $\begin{array}{c}\text { Total } \\
\text { estimate } \\
\text { d points }\end{array}$ & $\begin{array}{c}\text { Relative } \\
\text { importa } \\
\text { nce }\end{array}$ & $\begin{array}{c}\text { Total } \\
\text { estimate } \\
\text { d points }\end{array}$ & $\begin{array}{c}\text { Relative } \\
\text { importa } \\
\text { nce }\end{array}$ & $\begin{array}{c}\text { Total } \\
\text { estimate } \\
\text { d points }\end{array}$ & $\begin{array}{c}\text { Relative } \\
\text { importa } \\
\text { nce }\end{array}$ & $\begin{array}{c}\text { Total } \\
\text { estimate } \\
\text { d points }\end{array}$ & $\begin{array}{c}\text { Relative } \\
\text { importa } \\
\text { nce }\end{array}$ & $\begin{array}{c}\text { Total } \\
\text { estimate } \\
\text { d points }\end{array}$ & \\
\hline$\% 65.02$ & 396 & $\% 73.73$ & 449 & $\% 41.22$ & 251 & $\% 86.86$ & 529 & $\% 50.25$ & 306 & 1 \\
\hline$\% 68.47$ & 417 & $\% 58.13$ & 354 & $\% 73.73$ & 449 & $\% 78.16$ & 476 & $\% 54.52$ & 332 & 2 \\
\hline$\% 72.25$ & 440 & $\% 69.13$ & 421 & $\% 81.61$ & 497 & $\% 56.32$ & 343 & $\% 51.07$ & 311 & 3 \\
\hline$\% 74.55$ & 454 & $\% 87.36$ & 532 & $\% 69.29$ & 422 & $\% 70.60$ & 430 & $\% 73.40$ & 447 & 4 \\
\hline$\% 75.21$ & 458 & $\% 79.80$ & 486 & $\% 60.43$ & 368 & $\% 85.55$ & 521 & $\% 63.38$ & 386 & 5 \\
\hline$\% 50.57$ & 308 & $\% 88.67$ & 540 & $\% 71.26$ & 434 & $\% 80.46$ & 490 & $\% 61.25$ & 373 & 6 \\
\hline$\% 61.90$ & 377 & $\% 59.77$ & 364 & $\% 63.71$ & 388 & $\% 82.59$ & 503 & $\% 54.68$ & 333 & 7 \\
\hline$\% 67.49$ & 411 & $\% 72.25$ & 440 & $\% 64.86$ & 395 & $\% 72.09$ & 439 & $\% 63.71$ & 388 & 8 \\
\hline$\% 75.21$ & 458 & $\% 57.47$ & 350 & $\% 66.67$ & 406 & $\% 62.89$ & 383 & $\% 67.65$ & 412 & 9 \\
\hline$\% 69.95$ & 426 & $\% 61.08$ & 372 & $\% 70.61$ & 430 & $\% 65.68$ & 400 & $\% 36.95$ & 225 & 10 \\
\hline$\% 60.92$ & 371 & $\% 45.65$ & 278 & $\% 84.24$ & 513 & & & & & 11 \\
\hline$\% 75.70$ & 461 & $\% 54.02$ & 329 & $\% 55.17$ & 336 & & & & & 12 \\
\hline$\% 88.51$ & 539 & & & $\% 89.66$ & 546 & & & & & 13 \\
\hline
\end{tabular}

Table (5) highlighted the low percentages of the to the cooperation of the administrative system research sample responses in the administrative of the Tennis Federation with the tennis players domain, which confirms the existence of in meeting their needs. The researcher believes administrative obstacles based on the opinions that the reason behind is that people in charge of of the research sample. The highest percentage was given to managing the tennis activity in the club which was $73.40 \%$ and $67.65 \%$ in supplying the club with tennis courts and 63.71 administrative work are qualified.

The lowest percentages were given to the following:

- There is a tennis court at school for practicing tennis during $36.95 \%$ the school day.

- Dates of tennis championships don't interfere with the $50.25 \%$ school day.

- Playing tennis does not interfere with my school duties. $\quad 51.07 \%$

The researcher believes that this demonstrates the paucity or perhaps the non-existent of tennis courts at schools even though most tennis players practice tennis at high level schools that is supplied with tennis court which may be an important factor in helping the player to train and upgrade his level at school. Meanwhile, some schools may not have courts because they 
focus on the theoretical aspects and didn't give much attention to assist the player to practice and participate in championships, on the other hand, the dates of the tennis matches are not suitable for players, which confirms the need to return to the management systems to achieve the safe practice of the player as well as coordination between clubs and schools to avoid these obstacles. The results also show the necessity of the presence of the board members of the Tennis Federation among the players to get to know their needs and solve their problems. The percentage of the sentences of the administrative domain was low which indicates that there are administrative obstacles that faced tennis players.

The results of this research agreed with the results Ahmed Alsayed Metwally(1995) (3) , Ahmed Haggag (1999) (4), Barrows Patti Lynn (2003)(13) and Sarah Yonug (2003)(17) in the presence of some special administrative obstacles in the academic aspects of the players.

As shown in Table (5), the highest percentages of sample research responses was given to the financial domain, as it was $75 \%$ or more in the following phrases

- Playing tennis requires considerable financial costs.

- The cost of issuing Tennis Federation Cards is suitable for $78.16 \%$ players.

- Family pays for all the costs of playing tennis.

- The economic level of the family has a significant impact $80.46 \%$ on children's participation in tennis.

The researcher believes that one of the serious obstacles in tennis is the huge financial cost, which falls upon families of high economic level. The researcher also believes that the sport of tennis, through the opinions of the research sample, do not start from a broad base of participants because medium and low economic levels may not be able to participate or even just try tennis.

Lowest percentages were given to the following sentences

- The Tennis Federation supplies the players, who take part $56.32 \%$ in international championships, with their requirements.

- One of the reasons which make players quit tennis is the $62.89 \%$ high costs of practice.

- The club provides incentives for the high level tennis $65.68 \%$ players as a kind of encouragement.

The researcher supposes that this may be due to the inability of the Tennis Federation to provide the players with their financial requirements for participation in international championships, which in turn force parents to pay the costs. Beside, the most important reasons for the low rate of participation in tennis come from the high cost of training, tools ...etc. Beside, clubs where tennis is practiced provides unsatisfactory incentives for players as a kind of encouragement.
The results of this research agreed with the studies of Ahmed Alsayed Metwally (1995) (3), Sameh Abdul Muttalib Desouky (2006) (6), Ali Abdullah Hussein (2012) (8) and Alexandris (2002) (12) on the lack of the financial aspect.

It is shown in Table (5) from the answers of the research sample in the organization domain that the highest percentages, which reach the percentages of $75 \%$ or more was in the following phrases:

- The sport gear of the tennis players is suitable for matches.

- Computer systems used in the championships have a $84.24 \%$ positive impact on the participation.

- The clubs are having files for tennis players which contain $81.61 \%$ all their data. 
The researcher believes that this matter is related to the law of tennis which is abide by the uniform that gives the player a decent shape during practice and being stick to specific sizes for any signs of the manufacturer or merchant, as well as allowing girls to wear the Islamic dress code during the championships. In addition, computer systems and modern software, which the Tennis Federation is currently using, provide a lot of information on dates of championships and classification of players and results through the Global Information Network (Internet). Beside, the records are carried out by club administrators who are keen to help the technical staff of tennis.

Low percentages were given to the following sentences:

- The educational system in the Arab Republic of Egypt $41.22 \%$ support tennis players.

- The system of selecting players to represent the Egyptian $55.17 \%$ team is fair and neutral.

- Dates of organizing tennis matches are suitable for players. $60.43 \%$

- Dates stated in calendar of the Egyptian Tennis Federation $60.43 \%$ are adhered to.

The researcher believes that this may be due to the Egyptian educational system which does not seem to improve the tennis player that led the players to revert to external education, which sponsored their education and sportive affairs without any problems and this is one of the reasons behind the migration of players from their homeland. Besides, the selection of players for the team has no specific rules and may rely upon compliments which confirm the need to unify the criteria for selection. The times of the matches may not be appropriate for players who may miss the school for taking part in the championships which confirms the need to rearrange the calendar.

The research results agreed with studies of Ahmed Alsayed Metwally (1995) (3), Ahmed Haggag (1999) (4), Tariq Mohammed Abdul Sattar (2010)(7), Alexandris (2002) (12) and Sarah Yonug (2003)(17) regarding the deficiencies of the systems to achieve success in practicing this activity.

Table (5) shows the responses of the research sample on the coaching domain which has reached $75 \%$ or more in the following sentences:

- Coaches who train tennis are of different levels.

- Tennis coaching needs a greater time.

- I choose the coach whom I like to train with.

$79.80 \%$

The researcher believes that this is due to that tennis coaching starts at an early age and last for a long time and on a regular basis, as well as adhering to the training programs to participate in the tennis competitions. The tennis players start playing tennis at an early stage, which required coaches for each stage, such as coaches for beginners and coaches for other stages, as well as, the selection of the coach by the player which he feels that he has special training program that will contribute in his progress.

The sentences related to coaching domain, which got the lowest percentages were as follows:

- The Tennis Federation organizes training camps for $45.65 \%$ players.

- Tennis coaches are selected according to special terms and $54.52 \%$ conditions.

- Tennis federation supply information on coaching and $57.47 \%$ preparation of players.

- The club provides highly skillful coaches. $58.13 \%$

- Coaches are well qualified. 
The researcher believes that this is probably due to the lack of the education and refreshment of tennis coaches by the Tennis federation as well as the lack of facilitating the attendance of sessions and considers organizing such courses a source of income for the federation. The researcher, through his work in the field of tennis, believes that the majority of boys and workers of stadiums were converted to coaching without being adherence to any terms or conditions beside, there is a lack of clarity of the education systems of coaches in the Egyptian federation and the clubs support the job of coaching for any ineligible coach for which the

- Delaying matches later in the night negatively affects the $88.51 \%$ efficiency of the officials.

- The officiating of the match by a temporary official causes $75.70 \%$ problems.

- The relationship between officials and players is $75.21 \%$ characterized by appreciation and respect.

- Tennis officials are fit and capable to manage the matches. $75.21 \%$

The researcher believes that this is due to the continuity of the official to manage and officiate the matches for a long time until evening where they use the spotlight which in turn leads to the consumption of stadiums facilities as well as the fatigue of the officials due to the different atmosphere which adversely affect the efficiency of the officials. On the other hand, the officiating of matches by players in which the officials' role is to follow up the matches in many courts does not lead to being neutral in the federation has no power to do so, this confirms the need to reconsider the work of ineligible coaches in the federation and the Tennis Federation should undertake this task.

The results of this research get on with the research of Ahmed Alsayed Metwally (1995) (3) and Sameh Abdul Muttalib Desouky (2006) (6) on the importance of the coaching element in this activity.

Table (5) shows the answers of the research sample in the officiating domain which has got $75 \%$ or more in the following:

- Officiating of matches does not cause any problems for the $50.57 \%$ players

- Tennis Federation doesn't interfere in the work of the $60.92 \%$ officiating commission

match. The results also confirm that there is a mutual respect between officials and players. As for the fitness of the officials, it shows the good selection of officials according to certain conditions and criteria which are: to hold a university degree, to be excellent in a foreign language as well as being fit.... which confirmed the views of the sample.

The following sentences have got the lowest results: 
The researcher believes that this may be due to that the officials depend on their senses in the officiating process, in this way; the lack of experience of the officials is the reason behind the unintentionally injustice among players, which may cause problems in the match or lead to the inability of officials to issue immediate and decisive judgments.

The Tennis Federation may interfere in the work of the officials ' committee, as they had the right to appoint or depose the panel of judges, one of federation's committees working under its umbrella and that indicates the need for the officiating committees to work separately.

\section{Conclusions}

In light of the objectives of the research, and displaying its results and within the sample and throughout the domains of the questionnaire, we can conclude the following:

\section{The administrative domain}

- Dates of tennis championships are not convenient to the players.

- There is no encouragement from school to the players to play tennis

- Practicing tennis has negatively affected the academic achievement of the tennis players

- There are no tennis courts at schools for practicing tennis.

- Members of the Board of Directors of the Tennis Federation are not aware of the problems of the players.

\section{The financial domain}

- Tennis is a highly expenses activity which is not available for all social class.

- The family bears most of the expenses of their children's participation in tennis

- Tennis equipment are too expensive

- One of the reasons for the reluctance of interested players to play tennis is the rising costs of practice.

- The Tennis Federation insufficiently provides the requirements of the players who represent the federation abroad.

- Clubs do not offer satisfactory incentives for players as a kind of motivation for success.
- School system in the Arab Republic of Egypt does not encourage practicing tennis.

- The system of selecting players to represent the team is not characterized by justice and neutrality.

- Computer systems have a significant role in facilitating the practice of the activity in the federation.

- The sport gear of tennis players is well suited to the players.

\section{Coaching domain}

- The Tennis Federation doesn't appropriately held training camps for players.

- There are no clear criteria for the selection of tennis coaches.

- Tennis coaching requires unlimited time.

- Tennis Federation provides no facilities to prepare and refresh the coaches.

- The information provided by the Tennis Federation for coaching and education are very poor compared to its role in spreading the game.

\section{Officiating domain}

- The officiating of the match by a temporary official causes problems.

- Delay matches late in the night negatively affect the efficiency of the officials

- Officiating of matches may cause problems in the matches

- The relationship between officials and players is characterized by appreciation and respect.

\section{Recommendations}

In light of the objectives of the research and throughout presenting its findings and within the research sample, the researcher recommends the following:

1. The need to re-arrange the dates of the tennis championships to suit players.

2. Activating the role of the school to encourage the players through supporting the players and construct tennis courts at schools.

3. Reducing the prices of sports equipment in general and tennis in particular to make it easy for the player who wants to practice tennis.

\section{Organization domain}


4. Provide incentives for players who are unable to practice tennis such as tennis rackets, balls ...etc.

5. The clubs provides facilities for the top tennis players.

6. Activating the role of the Tennis Federation in providing facilities for people involved.

7. Reconsider the educational system in order to allow and encourage the practice of tennis.

8. To establish clear criteria which specify the methods of selecting the players who will represent the Egyptian team.

9. The need to develop criteria for the selection of tennis coaches who should have an adequate educational background.

10. Increase and support the camps for educating and refreshing the players and coaches by the Egyptian Tennis Federation.

11. The Egyptian Tennis Federation should provide adequate information on the practice of tennis which should be available to all without any charge.

12. The necessity to controls the postponing of matches late in the night.

13. Good educational system for officials in order to avoid complaints from officiating.

\section{References}

1. Ameen Al Kholy, Gamal El Shafei (2001): "Tennis is a series of photographic rocket games", Arab Publishing House

2. Ameen Al Kholy, Gamal El Shafei (2001): "Tennis - History - skills and plans - The rules of the game", Arab Publishing House.40,

3. Ahmed Alsayed Metwally (1995): "Studying the problems facing the national team coaches in the Arab Republic of Egypt", unpublished Master degree, Faculty of Physical Education, Helwan University.

4. Ahmed Ali Haggag Youssef (1995): "Academic obstacles of the national team players of the university students", unpublished Master, Faculty of Physical Education, Helwan University.
5. The Egyptian Tennis Federation (2012): "Competitions and regulations system", Cairo.

6. Sameh Abdul Muttalib Desouky (2006): "Obstacles of making Olympic champion in the light of the school sporting activities", unpublished Master, Faculty of Physical Education, Helwan University.

7. Tariq Mohammed Abdul Sattar Mohammad Saaed (2010): "An analytical study of the administrative problems that faced the management of sporting activities in Qenna Governorate Clubs", unpublished Master, Faculty of Physical Education, Helwan University.

8. Ali Abdullah Hussain Sayed (2012): "Obstacles of practicing sporting activities for middle school students of Azhar institutes in Fayoum Governorate", unpublished Master, Faculty of Physical Education, Helwan University.

9. Labib Abdel Aziz Labib (2003): "obstacles facing tennis officiating", Journal of Menoufia University of Physical Education and Sports, 3rd issue, the second year, 3rd volume.

10. The Gezira Sporting Club (2003): "The Gezira tennis", a non-periodic bulletin, The Gezira Sporting Club, the first issue. 12 ,

11. Nasser Abu Zaid Ali Ibrahim (2005): "The effectiveness of recreational training in the development of the technical performance of tennis players," unpublished Ph.D., Faculty of Physical Education, Helwan University.3,

12. Alexandris, K. Tsorbaizoudis, c \& Grouios, G (2002) : Perceived consataintson Recreational sport porticipotion investigating their relationship with intrinsic motivation and extrinsic motivation, Journal of Leisure Research.

13. Barrows- Patti- Lynn (2003) : Exercise participation and the Relationship to depressive sympiomstology matives, barriers, and perceived benefits of exercise parricipation in college students Texas- Tech- University.

14. Berrucci, B (1982) : Champion ship volleyball by experts, 2 nd press, S.S.A. 18 ,

15. International Tennis Federation (2012) : Men's circuir, rule book. 
16. Spoore dana (2003) : Planaing and design the centers of physical fitness for men.

17. Yoong, S, J., Ross, C. M \& Barcelona, R. J (2003) : Perceived constraints by college students to participation in campus recreational sports programs recreational sports journal. 